\title{
A conservation law for self-hydrolysis process of aqueous sodium borohydride
}

\author{
${ }^{1}$ School of Fashion, Zhongyuan University of Technology, Zhengzhou 450007, China \\ e-mail: phdliuhongyan@gmail.com; \\ ${ }^{2}$ National Engineering Laboratory for Modern Silk, College of Textile and Clothing Engineering, Soochow University, \\ 199 Ren-Ai Road, Suzhou 215123, China \\ ${ }^{3}$ Nantong Textile Institute, Soochow University, 58 Chong Chuan Road, Nantong, China
}

\section{ABSTRACT}

A conservation law is obtained for self-hydrolysis process of aqueous sodium borohydride, which gives an explicit relationship between the concentrations of $\mathrm{NaBH} 4$ and hydrogen ions during the global reaction.

Keywords: Sodium borohydride, Self-hydrolysis, Analytical model, Hydrogen storage.

\section{INTRODUCTION}

Excellent catalytic performance of $\mathrm{CoO}$ nanocrystals on the catalytic hydrolysis of alkaline $\mathrm{NaBH}_{4}$ solutions was observed experimentally, hydrogen generation from the hydrolysis of sodium borohydride ( $\mathrm{NaBH} 4)$ solution has drawn much attention recently, due to its high theoretical hydrogen storage capacity and potentially safe operation [1]. However, hydrolysis of $\mathrm{NaBH} 4$ for hydrogen generation is a complex process [1- $\underline{3}]$, and it is highly needed to have an explicit formulation to reveal concentration change in the reaction process.

The hydrolysis of $\mathrm{NaBH} 4$ is an exothermic reaction that yields hydrogen $(\mathrm{H} 2)$ gas and water-soluble sodium metaborate $(\mathrm{NaBO} 2)$. The global reaction of $\mathrm{H}_{2} \mathrm{O}$ and $\mathrm{NaBH} 4$ is given in the form [2] .

$$
\mathrm{NaBH}_{4}(a q)+2 \mathrm{H}_{2} \mathrm{O} \AA 4 \mathrm{H}_{2}+\mathrm{NaBO}_{2}(a q)+\mathrm{Heat}
$$

The rate of hydrolysis is a complicated reaction that is strongly dependent on solution temperature, $\mathrm{NaBH} 4$ concentration, the molar concentration of dissolved hydrogen ions, $\mathrm{H}+[\underline{2}]$ :

$$
\frac{d x}{d t}=A x^{a_{1}} y^{b_{1}}
$$

$$
\frac{d y}{d t}=B \exp \left(\frac{a_{2}\left(x_{0}-x\right)}{x_{0}}\right) y^{b_{2}}
$$

where $\mathrm{x}$ is NaBH4 concentration, $\mathrm{y}$ is $\mathrm{H}^{+}$concentration, ${ }^{x}$ the initial concentration of $\mathrm{NaBH} 4, \mathrm{~A}$ and $\mathrm{B}$ are constants depending upon temperature, $\alpha_{1}$ and $\beta_{1}$ represent the order of reaction for [NaBH4] and [H+], respectively. $\alpha_{2}$ and $\beta_{2}$ are the exponential constant and the order of reaction for [H+], respectively.

The system, Eqs. (2) and (3), can be effectively solved by some an analytical method, such as the variation iteration method, the homotopy perturbation method, and the parameter-expansion method $[4, \underline{5}]$. This paper aims to searching for a conservation law for self-hydrolysis process of aqueous sodium borohydride (NaBH4) for hydrogen generation purpose. 


\section{CONSERVATION LAW}

From Eqs. (2) and (3), we have

$$
\frac{d x}{d y}=\frac{A x^{a_{1}} y^{b_{1}}}{B \exp \left(\frac{a_{2}\left(x_{0}-x\right)}{x_{0}}\right) y^{b_{2}}}
$$

or

$$
B \exp a_{2} x^{-a_{1}} \exp \left(-a_{3} x\right) d x=A y^{b_{1}-b_{2}} d y
$$

$$
\text { where } \alpha_{3}=\alpha_{2} / x_{0} \text {. }
$$

Integrating Eq. (5) results in

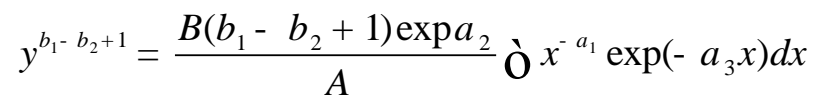

Eq. (6) is the conservation law for the self-hydrolysis process, which implies whatever the process continues, the concentrations of $\mathrm{NaBH} 4$ and hydrogen ions must follow Eq. (6).

\section{CONCLUSIONS}

This work focuses on concentration changes of $\mathrm{NaBH} 4$ and $\mathrm{H}+$ of the self-hydrolysis of sodium borohydride, the conservation law, Eq.(6), reveals the relationship between concentrations of NaBH4 and $\mathrm{H}+$ in the global reaction process. The integration constant involving in Eq.(6) can be determined by the initial concentrations, and the conservation law can be used to predict the reaction process by the $\mathrm{pH}$ value of the solution, which is a measure of the molar concentration of dissolved hydrogen ions.

\section{ACKNOWLEDGMENTS}

The work is supported by Priority Academic Program Development of Jiangsu Higher Education Institutions (PAPD), National Natural Science Foundation of China under grant No. 61303236 and No.11372205 and Project for Six Kinds of Top Talents in Jiangsu Province under grant No. ZBZZ-035, Science \& Technology Pillar Program of Jiangsu Province under grant No. BE2013072, Jiangsu Province Key Laboratory No.KJS1314 and Jiangsu Planned Projects for Postdoctoral Research Funds1401076B.

\section{BIBLIOGRAPHY}

[1] RETNAMMA R., NOVAIS A.Q., RANGEL C.M., "Kinetics of hydrolysis of sodium borohydride for hydrogen production in fuel cell applications: A review”, International Journal of Hydrogen Energy, vol.36, n.16, pp. 9772-9790, 2011.

[2] BARTKUS T.P., TIEN J.S., SUNG C.J., “A semi-global reaction rate model based on experimental data for the self-hydrolysis kinetics of aqueous sodium borohydride", International Journal of Hydrogen Energy, v.38, n.10, pp. 4024-4033, 2013.

[3] LU A., CHEN Y., JIN J., et al., "CoO nanocrystals as a highly active catalyst for the generation of hydrogen from hydrolysis of sodium borohydride”, Journal of Power Sources, v.220, pp.391-398, 2012.

[4] HE J.H., "Some asymptotic methods for strongly nonlinear equations", International Journal of Modern Physics B, v.20, pp.1141-1199, 2006.

[5]HE,J.H., KONG,H.Y., et al. Variational iteration method for Bratu-like equation arising in electrospinning, Carbohydrate polymer, v.105, pp.229-230, 2014 